\title{
The method of extending drone piloting autonomy when monitoring the technical condition of 6-10 kV overhead power lines
}

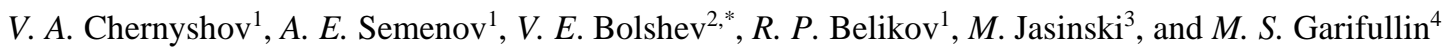 \\ ${ }^{1}$ Orel State Agrarian University, Orel, Russia \\ ${ }^{2}$ Federal Scientific Agroengineering Center VIM, Moscow, Russia \\ ${ }^{3}$ Wroclaw University of Science and Technology, Wrocław, Poland \\ ${ }^{4}$ Kazan State Power Engineering University, Kazan, Russia
}

\begin{abstract}
The paper considers options for the implementation of the technical condition monitoring of the of power supply system elements, the assessment of overgrowing of the power line routes using an unmanned aerial vehicle. A method for emergency control of an unmanned aerial vehicle used to monitor the technical condition of $6-10 \mathrm{kV}$ overhead power lines has been proposed. This method is used in case of loss of radio communication between the unmanned aerial vehicle and the ground control station. The method is based on the activation of the automatic piloting system allowing the unmanned aerial vehicle flight to continue to the pre-determined emergency landing area. The autopilot is carried out by means of a servo controller and sensitive sensors reacting to the intensity of the electromagnetic field of a $6-10 \mathrm{kV}$ overhead power line.
\end{abstract}

\section{Introduction}

Power network inspection includes several types of work. Among them there is the determination of the technical condition of network equipment, in particular, supports and wires of power transmission lines, transformer substation cabinets, etc [1-3]. In addition to the equipment state, it is necessary to identify the risks of damage to this equipment arising from external factors and possible causes of power outages in the network $[4,5]$. As the statistics analysis [6-8] shows, the main reason for power outages is overlapping through tree branches, wire breakages by trees. That is, it is necessary to identify the overgrowing of the tracks and timely apply measures to clean them from trees. It is also necessary to determine the characteristics of power network operating modes, and it is desirable to receive them without disconnecting consumers in order to avoid under-supply of electricity as well as to determine the real parameters of the network operating modes.

The total length of $0.4(0.38) \mathrm{kV}$ power lines in Russia is more than 770 thousand kilometers [9]. For this reason, it is impossible to equip all power lines of this voltage with stationary monitoring systems. Therefore, it is necessary to create mobile measuring complex (MMC) [10], which make it possible to conduct a survey of a large number of power lines in a rather short period of time. For today the existing mobile electrical laboratories are mainly intended for testing and diagnosing electrical equipment of substations, switchgears and cable lines, measuring insulation resistance of power and current transformers, highvoltage switches and relay protection. They are also used to locate damage to cable lines using precise pre-location methods. Most often they are used when disconnecting consumers and do not allow to solve a number of important tasks such as taking parameters of network operation modes.

\section{Development of an emergency control system for a UAV}

Currently, there is a tendency of an avalanche-like growth of the all-round use of various unmanned aerial vehicles (UAV) by both military and civilian structures [11-13]. Variants of using the UAV are also being actively developed for the power industry needs, namely, for monitoring the technical condition of $6-10 \mathrm{kV}$ power lines [14-16]. Figure 1 shows a photo of a UAV test developed in the Orel SAU.

The UAV inclusion in the structure of the mobile measuring system will effectively detect the causes of future damage, failures. The number of failures in networks will decrease due to the timely elimination of these causes. Unfortunately, there are no significant statistics on the UAV use for power line monitoring in Russia. But it is possible to draw an analogy with other industries and assume what will affect the reduction in the number of accidents on power lines.

\footnotetext{
* Corresponding author: vadimbolshev@gmail.com
} 


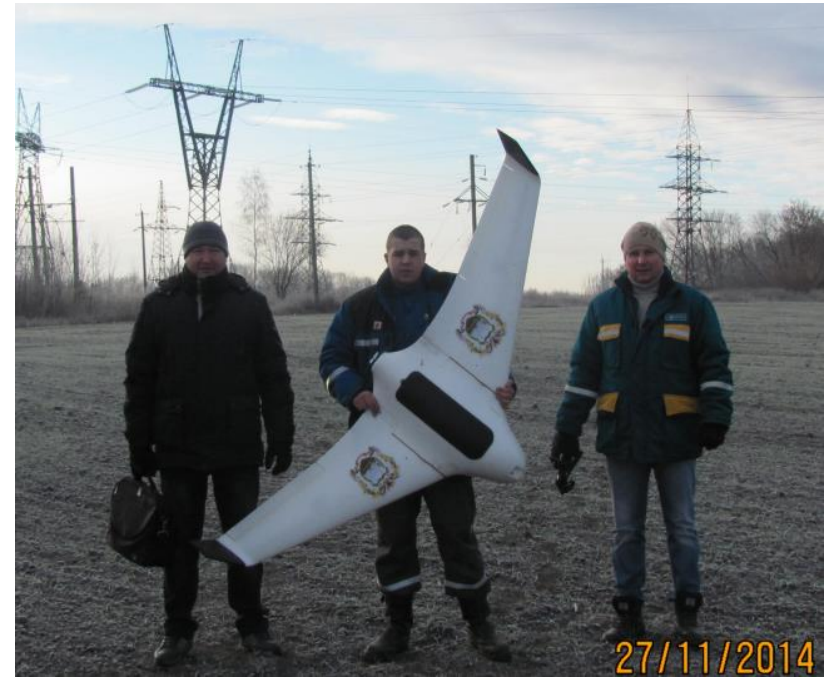

Fig. 1. Photo from the place where the UAV is tested Mtsensk District of Electric Networks, branch of IDGC of Center - Orelenergo.

So according to the results of the use of Tomskneft UAVs over the past five years, the number of failures on the company pipelines has decreased by almost $45 \%$ due to the use of UAVs for monitoring. [17].

In some cases, the UAV use helps to reduce the time spent on detecting the failure place, that is, the information recognition time. For example, the branch of IDGC of Center - Orelenergo tested the UAV developed at the Electrical Power Supply Department of the Oryol State Agrarian University, the test showed that the time of power line inspection was reduced from 3 hours to $5 \ldots 15$ minutes for $1 \mathrm{~km}$ power line, that is, more than 30 times [18]. Accordingly, the UAV use can reduce the cost of power line inspection since they can be used to examine large power lines for the same time.

This work includes the study of a number of issues related to improving the UAV design, autonomous flight control using data from satellite navigation systems as well as automated collection and processing of hardware and visual information on the $6-10 \mathrm{kV}$ overhead power line state. A program has been developed that makes it possible to determine the most promising option for monitoring the transmission line state depending on environmental conditions, landscape and other factors [19].

To date, there are several ways to control UAVs:

- Remotely piloted method including: manual control carried out by the operator in real time and automated control carried out autonomously, but with the possibility of making changes to the flight task by the operator;

- Automatic control performed by autopilot on a predetermined trajectory at a selected height with a selected speed and with stabilization of orientation angles.

A remotely piloted method is the most promising one at the present time. It allows real-time monitoring of the necessary terrain and objects as well as participating in rescue operations. The operator from the ground control station flights controls the aircraft or makes adjustments to the flight task by means of cameras located on the UAV [20].

Despite the fact that modern UAV automatic control systems seem to be very advanced, scientific and technological progress opens up new possibilities to modernize them. However, the simple saturation of UAVs with complex automated control systems increases the UAV cost along with the likelihood of failures in complex automated systems what can result in the its loss. In this regard, the UAV hardware has very high requirements for providing the necessary technical parameters and characteristics. Among them special attention is paid to ensuring the reliability and safety of remote UAV piloting, ensuring anti-shock, dust and moisture protection, radio protection as well as ensuring electromagnetic compatibility with $6-10 \mathrm{kV}$ overhead lines [20].

A problematic issue in the UAV operation during a survey of power transmission lines is the probability of UAV loss when communication with it disappears. In this case, it is necessary to provide solutions aimed at emergency autonomous control of UAVs.

The authors of this publication consider the method of emergency UAV control monitoring the technical condition of a 6-10 kV overhead line which can be implemented in case of loss of radio communication between the UAV and the ground control station. The proposed control option involves the continuation of the UAV flight along the $6-10 \mathrm{kV}$ overhead line, while the UAV is controlled by an emergency autopilot with a servo controller (SC) that uses sensitive elements as the source of control signals. These elements are a capacitive antenna sensor and an inductance coil reacting to the electromagnetic field of $6-10 \mathrm{kV}$ overhead power lines [21]

One of the most important elements of modern automated control systems for various objects including unmanned aerial vehicles are a servo controller. The servo controller is most widely used in industry and military technology to control the position of objects with a high degree of accuracy.

A servo controller is a closed dynamic system that accurately reproduces an arbitrary time-varying input signal at the output, for example, providing an exact repetition of movements that overcome any efforts [22]. Simply put, it can be formulated in such a way - the remote control of UAV is available to the operator through a servo controller by means of easily changing the position of the manipulator arm on the control panel.

Antenna sensor consists of several series-connected elements, made in the form of loops of insulated wire. These loops have a capacitance relative to the wires of an 6-10 kV overhead power line, so a voltage proportional to the overhead line operating voltage is generated on them. Then the voltage is amplified and enters automatic emergency piloting unit in the form of a driving signal.

The inductance coil perceives an inductive response to the current in the $6-10 \mathrm{kV}$ overhead power lines and serves to automatically calibrate the distance from the UAV to the given power lines, since the load current of 


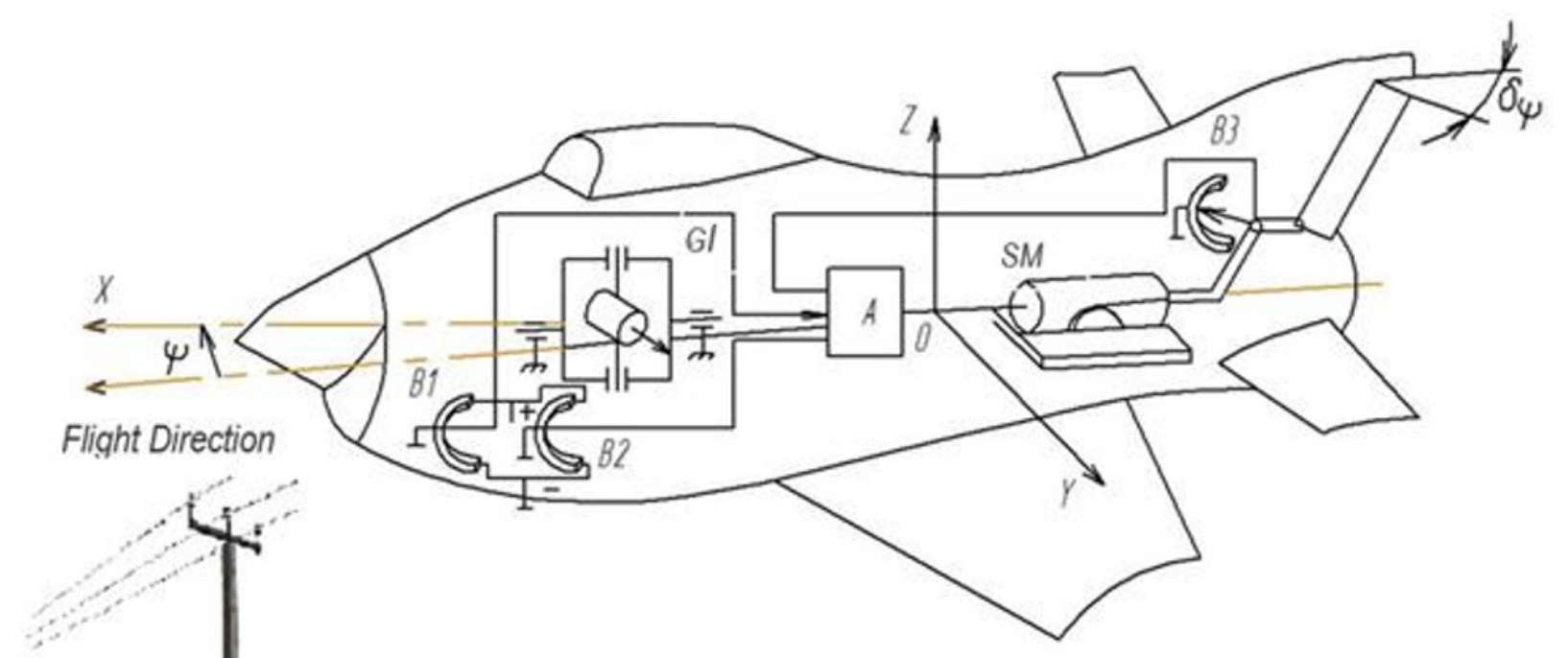

a)

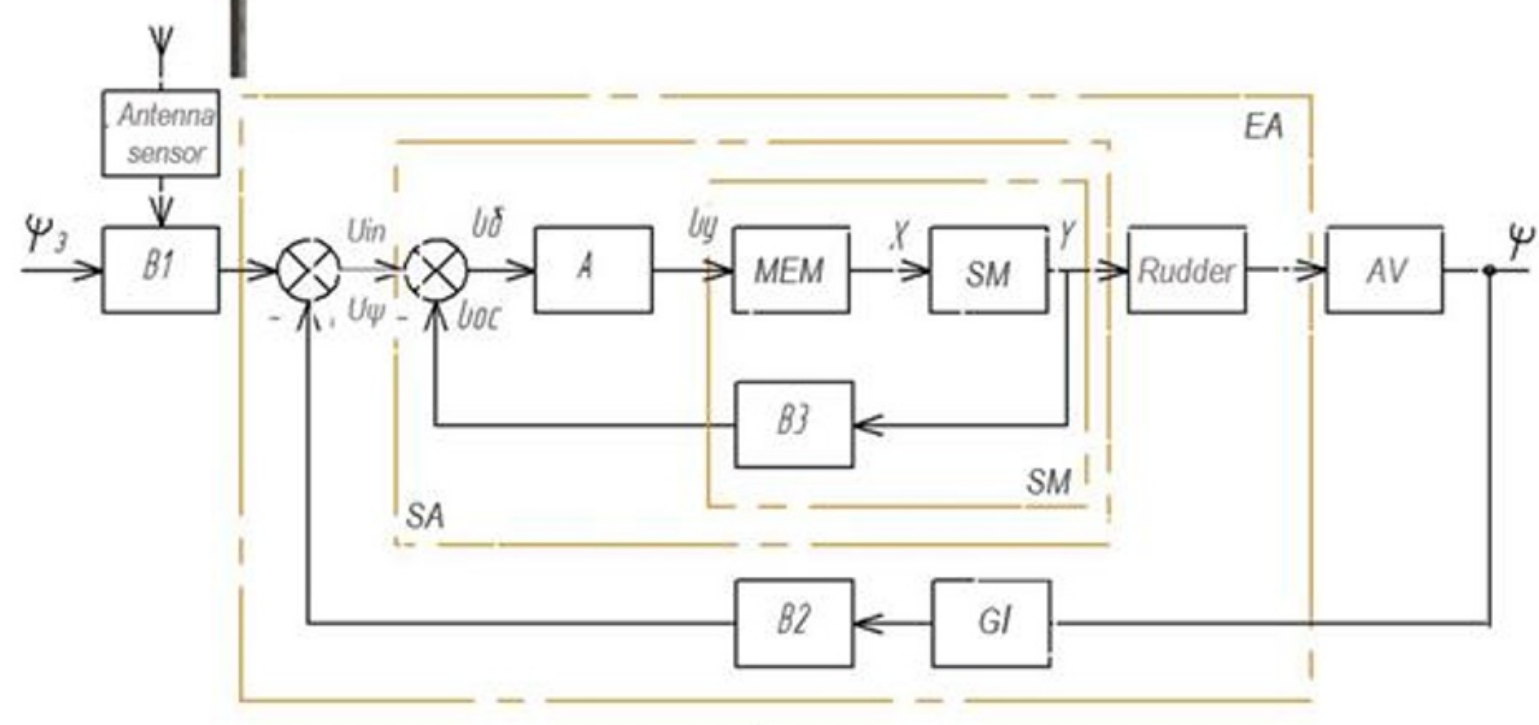

b)

Fig. 2. UAV flight control along the 6-10 kV overhead power lines: a - Functional scheme, b- Structural scheme.

the line affects the total voltage induced in the capacitive antenna sensor.

The capacitive antenna sensor and the inductance coil installed in the UAV nose allow the emergency autopilot to position the UAV via the SC and ensure its flight mode to stabilize at a constant rate relative to the $6-10$ $\mathrm{kV}$ overhead lines.

The classic functional and structural schemes of the UAV flight control along the $6-10 \mathrm{kV}$ overhead power lines is presented in Figure 1 [22]. The structural scheme includes two circuits: internal (steering motor (SM) providing flight mode stabilization at a constant course $\left(\psi_{3}=\right.$ const $)$ ), and external (emergency autopilot (EA) designed for automatic emergency flight control (course change)).

The controlled object of the external circuit is the $\mathrm{UAV}$, the output coordinate is the yaw angle $\psi$ (the angle between the conventional line of the magnetic field of power line and the path of UAV flight). A gyro instrument (GI) is used to measure the angular position of the UAV. The GI axis is pre-set along the longitudinal axis of the UAV. The GI axis serves as a course indicator keeping its position unchanged during a flight. In the stabilization mode, when the UAV deviates from the set course, potentiometer B2 fixed in the UAV case

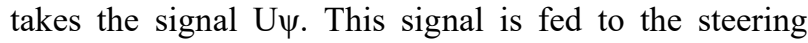
actuator (SA) rejecting the UAV rudder. When the rudder is deflected, an aerodynamic moment arises relative to the $\mathrm{OZ}$ axis, turning the plane along the course along the $6-10 \mathrm{kV}$ high-voltage line until the signal from B2 is equal to zero. The UAV turns to the course is carried out by the formation of the corresponding task to the setting potentiometer B1 electrically connected with the potentiometer B2 GI. The corresponding task is issued by an automatic emergency piloting unit (in this case acting as an SC operator). It should be noted that the subsystem of UAV stabilization in height relative to $6-10 \mathrm{kV}$ overhead lines works in a 
similar way. The stabilization functions as a function of amplifying (attenuating) the electromagnetic field strength of $6-10 \mathrm{kV}$ overhead lines, continuously detected by a capacitive antenna sensor.

The method ensures the SM actuation, the steering deviation and the turn of the UAV at a given angle in the control mode and in the presence of a mismatch error Uin.

The internal circuit is the actuating device of the control system (external circuit) and at the same time an independent SC. The controlled object of this SC is the rudder, the output coordinate is the rudder position $\delta \psi$. To determine the position of the rudder in the feedback of the operating system is a potentiometer B3, the signal $\mathrm{Ub}$ from which is compared with the control signal Uin. The difference signal $U \delta$ is amplified in amplifier (A) and is fed to the steering machine (SM) rejecting the UAV steering wheel until the mismatch error disappears. An electric steering machine is used as the SM (Figure 1b), which includes a mechanical gearbox, a microelectric motor and a feedback potentiometer B3 [22].

\section{Conclusions}

The proposed method of creating an emergency control system for a UAV greatly increases the reliability of UAV remote piloting in the case of a loss of radio communication with a ground control station when monitoring the technical condition of a $6-10 \mathrm{kV}$ overhead line. Thus, it increases the safety of UAV flight, which helps prevent material damage associated with the fall and loss of the UAV.

\section{References}

[1] A. Vinogradov, A. Vasiliev, V. Bolshev, A. Semenov, M. Borodin, Time factor for determination of power supply system efficiency of rural consumers. Handbook of Research on Renewable Energy and Electric Resources for Sustainable Rural Development (Hershey, PA: IGI Global) 394-20. DOI:10.4018/978-15225-3867-7.ch017 (2018)

[2] C. Sampedro, C. Martinez, A. Chauhan, P. Campoy, A supervised approach to electric tower detection and classification for power line inspection. International Joint Conference on Neural Networks (IJCNN) (IEEE) 1970-1977. DOI: 10.1109/IJCNN.2014.6889836 (2014)

[3] A. Pagnano, M. Höpf, R. Teti, A roadmap for automated power line inspection. Maintenance and repair. Procedia Cirp. 12, 234-9. DOI: 10.1016/j.procir.2013.09.041 (2013)

[4] A. Vinogradov, A. Vasiliev, V. Bolshev, A. Vinogradova, T. Kudinova, N. Sorokin, N. Hruntovich, Methods of Reducing the Power Supply Outage Time of Rural Consumers. Renewable Energy and Power Supply Challenges for Rural Regions (Hershey, PA: IGI Global) 370-92. DOI: 10.4018/978-1-5225-9179-5.ch015 (2019)

[5] H.C. Caswell, V.J. Forte, J.C. Fraser, A. Pahwa, T. Short, M. Thatcher, V.G. Werner, Weather normalization of reliability indices. IEEE Transactions on Power Delivery 26(2), 1273-9. DOI: 10.1109/TPWRD.2010.2078839 (2010)

[6] A.V. Vinogradov, A.V. Vinogradova, I.D. Skityova, A.A. Panfilov, Sravnitelnyi analiz nadezhnosti elektrosnabzheniia po raionam elektricheskikh setei [Comparative analysis of the reliability of power supply in the areas of electrical networks]. Innovations in agriculture 3(28), 39-46 (2018)

[7] R.J. Campbell, S. Lowry, Weather-related power outages and electric system resiliency. (Washington, DC: Congressional Research Service, Library of Congress) (2012)

[8] P. Kankanala, S. Das, A. Pahwa, AdaBoost+: An Ensemble Learning Approach for Estimating Weather-Related Outages in Distribution Systems. IEEE Transactions on Power Systems 29(1), 359-67 DOI: 10.1109/TPWRS.2013.2281137 (2013)

[9] PJSC ROSSETI. STO 34.01-21.1-001-2017. Raspredelitel'nye elektricheskie seti napryazheniem 0,4$110 \mathrm{kV}$ [Distributive electric networks of 0.4-110 kV]. Standard of organization. Introduction date: 08.02.2017.

[10] A. Vinogradov, V. Bolshev, A. Vinogradova, M. Borodin, A. Bukreev, I. Golikov, Mobile Measuring Complex for Conducting an Electric Network Survey. Handbook of Research on Energy-Saving Technologies for Environmentally-Friendly Agricultural Development (Hershey, PA: IGI Global) 243-267. DOI: 10.4018/9781-5225-9420-8.ch010 (2020)

[11] J.A. Berni, P.J. Zarco-Tejada, L. Suárez, E. Fereres, Thermal and narrowband multispectral remote sensing for vegetation monitoring from an unmanned aerial vehicle. IEEE Transactions on geoscience and Remote Sensing, 47(3), 722-38. DOI: 10.1109/TGRS.2008.2010457 (2009)

[12] F. Nex, F. Remondino, UAV for 3D mapping applications: a review. Applied geomatics 6(1), 1-5. DOI: https://doi.org/10.1007/s12518-013-0120-x (2014)

[13] D. Orfanus, E.P. de Freitas, F. Eliassen, Selforganization as a supporting paradigm for military UAV relay networks. IEEE Communications Letters 20(4), 804-7. DOI: 10.1109/LCOMM.2016.2524405 (2016)

[14] Z. Li, Y. Liu, R. Hayward, J. Zhang, J. Cai, Knowledge-based power line detection for UAV surveillance and inspection systems. 23rd International Conference Image and Vision Computing (New Zealand) 1-6. DOI: 10.1109/IVCNZ.2008.4762118 (2008)

[15] D. Jones, Power line inspection-a UAV concept. The IEE Forum on Autonomous Systems (Ref. No. 2005/11271) p 8. DOI: 10.1049/ic:20050472 (2005)

[16] G. Zhou, J. Yuan, I.L. Yen, F. Bastani, Robust real-time $U A V$ based power line detection and tracking. 2016 IEEE International Conference on Image Processing (ICIP) 744-748. DOI: 10.1109/ICIP.2016.7532456 (2016)

[17] Tomskneft' nachala ispytaniya bespilotnikov dlya inspekcii truboprovodov [Tomskneft began testing drones for pipeline inspection] [Internet] [cited 2019 Mar 30]. Available from: http://www.riatomsk.ru/article/20150227/tomskneftj- 
nachala-ispitaniya-bespilotnikov-dlya-inspekciitruboprovodov/

[18] REHS OAO «MRSK Centra» «Orelehnergo» Protokol №1 ispytaniya bespilotnogo letatel'nogo apparata (BPLA OSLEHP Orel GAU) dlya osmotra VL na baze Mcenskogo REHS OAO «MRSK Centra» - «Orelehnergo» ot 26.11.2014g. [Protocol of the test of an unmanned aerial vehicle for inspection of overhead lines on the basis of Mtsensky REHS OAO «MRSK Centra» - «Orelehnergo», dated November 26, 2014.] (2014)

[19] A.V. Vinogradov, A.N. Sinyakov, A.E. Semenov, Komp'yuternaya programma po vyboru sistemy monitoringa tekhnicheskogo sostoyaniya vozdushnyh linij elektroperedachi [A computer program for choosing a system for monitoring the technical condition of overhead power lines] // Agrotechnology and energy supply 3(12), 52-61 (2016)

[20] I.A. Fomina, Metod testirovaniya ustojchivosti telekommutacionnoj sistemy upravleniya bespilotnyh letatel'nyh apparatov $k$ vozdejstviyu sverhkorotkih elektromagnitnyh impul'sov [Method for testing the stability of a telecommutation control system of unmanned aerial vehicles to the effects of ultrashort electromagnetic pulses] (Moscow, Russia): dis. ... Cand. econ Sciences: 05.12.13 - Systems, networks and devices of telecommunications (2015)

[21] E.I. Penovic, Otyskanie zamykanij na zemlyu $v$ raspredelitel'nyh setyah 6-10 $\mathrm{kV}$ [Finding earth faults in distribution networks 6-10 kV] (Moscow, Russia: Energy) (1975)

[22] V.I. Smirnova, V.I. Razintsev, Proektirovanie $i$ raschet avtomatizirovannyh privodov [Design and calculation of automated drives] (Moscow, Russia: Mashinostroenie) (1990) 